\title{
Discerning and Implementing Differentiated Instruction to Move TEFL Class towards Expertise
}

\author{
Dr. K. Yugandhar \\ Associate Professor \\ Department of English \\ Dilla University, Dilla, Ethiopia
}

\begin{abstract}
Almost every English language class these days are heterogeneous in terms of students' capacities, interests and pace of learning. Students with very advanced learning skills and students who struggle mightily with understand and using English are in one class. The language teacher facing such a diverse class with distinct levels of ability has to address the problem of how to meet the needs of everyone in the class. Against this background, this paper analyzes the needs of good and poor learners in a mixed ability class and to suggest principles for the refinement of high-quality instruction called "differentiation." Based on the variations while learning/using language, the learners are broadly classified as advanced learners and struggling learners. The teacher needs to plan and prepare the class according to their learning profiles to make them responsible for their own learning. The paper focuses on understanding variations learning profiles of students, the needs of advanced and struggling learners, suggests a few principles that are useful to ensure the learners to maximize their learning and proposes some guidelines for learning-profile differentiation. The teacher orchestrates the groups of mixed abilities with differentiated instruction using different materials and activities suitable for everyone in the class.
\end{abstract}

Keywords: TEFL class, Differentiated Instruction, Advanced and Struggling Learners, Differentiating Learning Experiences.

\section{INTRODUCTION}

Generally, an English language class is a combination of students of diversified abilities as they are from different backgrounds with differences in learning styles, learning speeds. Students from multiple backgrounds trying to bridge the languages and behaviour. Students with very advanced learning skill set sit next to the students who struggle mightily to understand and use English language. The teacher can provide high-quality instruction using "differentiation" in such diverse classes with students of varying abilities in understanding and using English. Differentiated instruction is a way to reach students with different learning styles, different abilities to absorb information and different ways of expressing what they have learned.

Differentiation is a teacher's reflection to learners' academic needs. It is simply attending to the learning needs of a particular student or small group of students rather than the more typical pattern of teaching the whole class as though all individuals in it were basically the same. As the aim of a differentiated class is maximum student growth and individual success, teaching and learning takes place effectively in classrooms where information is clearly and effectively organized, students are highly active in the learning process, assessments are of quality and varied, and students feel a sense of safety and association (Wiggins \& McTighe, 1998). Learning happens best when a learning experience pushes the learner a bit beyond learner's independence level. When a student continues to work on understandings and skills already mastered, s/he learns very little if any new learning takes place. On the other hand, if tasks are far ahead of a student's current point of mastery, frustration results and learning does not (Howard, 1994; Vygotsky, 1962). Thus Stephen Krashen suggests that the input given to a learner should be one step beyond the learner's current point of mastery. Then the environment of learning will be ideal. Motivation to learn increases when we feel a kinship with, interest in, or passion for what we are attempting to learn. Students go about learning in a wide variety of ways, based on individual interest, culture, and gender. 


\section{Dr. K. Yugandhar}

Differentiation of Instruction is a teacher's response to learner's needs guided by general principles of differentiations such as respectful tasks, flexible learning and ongoing assessment and adjustment. Teacher can differentiate content, process and product according to student's readiness, interests and learning profile through a range of instructional and management strategies. Ensuring clarity about where a language teacher expects students to end up as a result of a sequence of learning is fundamental to educational success. Depending on the learners' present levels and desired levels the teacher facilitates different materials / information/ guidelines / activities to different groups of students in the class. Offering multiple and varied avenues to learning is a hallmark of the differentiated instruction. This is necessary because students of the same class are not all alike when it comes to language learning they are different in terms of their learning / acquiring the language.

\section{DisCerning The NeEdS OF AdVANCED Learners}

There are four categories of learning-profile factors, and teachers can use them to plan curriculum and instruction that fit learners. There is some overlap in the categories, but each has been well researched and found to be important for the learning process. A student's learning style, intelligence preference, gender, and culture can influence learning profile. In spite of variations in learning profiles, some students may be advanced in the first semester and not in the second semester. Some may be advanced in speaking, but not in reading; or in writing, but not in listening. Some may be advanced for a short time, others throughout their lives but only in certain endeavors. Some learners are consistently advanced in many areas.

Because the primary intent of differentiated instruction is to maximize student's linguistic proficiency, when a teacher can find or have a hunch that a student can learn more deeply, better to move at a brisker pace, or make more connections than instructional blueprints might suggest, that's a good time to offer advanced learning opportunities. But advanced learners, like other learners, need help in developing their abilities. Without teachers that coach for growth and curriculums that are appropriately challenging, these learners may fail to achieve their potential. There are many reasons why advanced learners don't achieve their full potential.

> May become mentally lazy, even though they do well in the class.

$>$ May become "hooked" on the trappings of success.

May become perfectionists.

$>$ May fail to develop a sense of self-efficacy.

$>$ May fail to develop study and coping skills.

Advanced learners, like all learners, need learning experiences designed to fit them. When teachers are not sensitive to that need, they may set learning goals for advanced students that are too low or that develop new skills too infrequently. Then, if students are successful anyhow, they often fail to develop the desirable balance between running into walls and scaling them. Advanced learners share other learners' need for teachers who can help them set high goals, devise plans for reaching those goals, tolerate frustrations and share joys along the way, and sight new horizons after each accomplishment. After understanding the needs of advanced learners, a few practical thoughts that help to mentor them are mentioned as under:

$>$ Continually raise the ceilings of expectations so that advanced learners are competing with their own possibilities rather than with a norm.

$>$ Make clear what would constitute excellence for the advanced learner so s/he knows, at least in large measure, what to aim for in the work.

$>$ As you raise ceilings of expectation, raise the support system available to the student to reach his goals.

$>$ Be sure to balance rigor and joy in learning. It's difficult to imagine a talented learner persisting when there is little pleasure in what the learner once thought was fascinating.

\section{Discerning The NeEdS Of Struggling LeARNers}

One student's struggle stems from a learning disability, another's home life takes all her energy, and another just finds a subject his nemesis. Just like with an advanced learner, the learning profile of a 
struggling learner may shift over time; for example, suddenly a student becomes an eager reader after trailing the class in decoding and comprehension for some time. Many students whom we perceive to be "slow," "at-risk," or "struggling," may actually be quite proficient in talents that schools often treat as secondary, such as leadership among neighborhood peers, storytelling, or building contraptions out of discarded materials.

$>$ May become shy and timid, even though they do well in the class.

$>$ May become "hooked" on the trappings of failure.

> May suffer from inferiority / superiority complex.

D May fail to develop a sense of self-efficacy.

> May fail to develop study and coping skills.

Nonetheless, many students do struggle with the language tasks. They are a diverse group who can challenge the artistry of the most expert teacher in listening deeply, believing unconditionally, and moving beyond a recipe or blueprint approach to teaching to shape classrooms that offer many avenues and timetables to understanding. After understanding the needs of struggling learners, a few practical thoughts that help to take special care of them are discussed as under:

$>$ Look for the struggling learner's positives. Every student does some things relatively well. It's important to find those things, to affirm them in private conversations and before peers, to design tasks that draw on those strengths, and to ensure that the student can use strengths as a means of tackling areas of difficulty.

$>$ Encourage their strengths rather than focusing on their weaknesses: The difference between teachers and students is that teachers have a choice. Struggling learners are more likely to retain motivation to learn when their days allow them to concentrate on tasks that are relevant and make them feel strong. It's important to avoid the temptation of looking at their weaknesses.

$>$ Pay attention to relevance for each day. Learners don't "do school" well today, and teachers keep insisting that perseverance will pay off "someday"-often in the future. Dewey (1938) reminds us that if school isn't for today, it will often turn out to be for nothing. He believed this to be true for all learners. Certainly it is so for many struggling learners. A skilled teacher conscientiously works to make each day's explorations compelling for that day.

$>$ Teach according to learning profiles. Know your struggling students' learning profiles to understand their learning styles. Create tasks for struggling learners (individuals or groups with similar profiles) that are a chunk more difficult than you believe they can accomplish. Then teach for success by encouraging, providing support, guiding planning, delineating criteria, and so on.

> Use many opportunities to learning. Some students learn best with their ears, some with their eyes, and some with touch or movement. Some are solitary learners; some must interact with friends in order to learn. Some students work well by gathering details and constructing a bird'seye view of what is being studied. Others will not learn unless the bird's-eye view is clear to them before they encounter the details. Struggling learners sometimes become more successful learners just because their way of learning is readily accessible through both teacher design and student choice.

The teacher becomes as keepers and dispensers of knowledge and move toward themselves as organizers of learning opportunities. They enable students to take responsibility for their own learning under their mentoring. These teachers assess students' readiness through a variety of means, analyze and interpret student clues about interests and learning preferences, create a variety of ways students can gather information and develop varied ways students can explore and 'own' ideas and present varied channels through which students can express and expand understanding.

\section{FleXibilities for EfFECTIVE LEARNing AmbianCE}

In a differentiated classroom, a number of things are going on in any given class period. Over time, all students complete assignments individually and in small groups, and whole-group instruction occur as well. Sometimes students select their group size and tasks, sometimes they are assigned. Sometimes the teacher establishes criteria for success, sometimes students do. The teacher thinks and plans in terms of "multiple avenues to learning" for varied needs, rather than in terms of "normal" and "different." The goal for each student is maximum growth from his current "learning position." 
Learning profile refers to ways in which we learn best as individuals. Each of us knows some ways of learning that are quite effective for us, and others that slow us down or make learning feel awkward. Common sense, experience, and research suggest to us that when teachers can tap into routes that promote efficient and effective learning for students, results are better. The goals of learning-profile differentiation are to help individual learners understand modes of learning that work best for them, and to offer those options so that each learner finds a good learning fit in the classroom. The following principles are suggested for facilitating differentiated learning experiences:

1. Flexible class: Demonstrating clarity about learning goals, both teachers and students understand that time, materials, modes of teaching, ways of grouping students, ways of expressing learning, ways of assessing learning, and other class elements are tools that can be used in a variety of ways to promote individual and whole-class success.

2. Effective and ongoing assessment of learner needs: Student differences are expected, appreciated, and studied as a basis for instructional planning. This thoughts reminds us of the relation that should exist between assessment and instruction. Teachers need to recognize where students are in a relation to the teaching and learning goals with a focus to teach most effectively aiming learning needs and interests.

3. Flexible grouping for variety of learning opportunities: Teachers plan student working arrangements that vary widely and purposefully over a relatively short period of time. Such flexible grouped classes utilize whole-class, small-group and individual explorations effectively.

Sometimes, students learn and practice in a similar readiness groups with peers who manifest similar academic needs at a given time. At other times, the teacher ensures that students of mixed readiness work together in situations that draw upon the strengths of each students. Thus homogenous and heterogeneous groups contribute according the needs of the class.

\section{A FeW GUidelines for LEARning-ProfiLe DifFERENTIATION}

Though there is no single way of ensuring that students get to learn in ways that work best for them, some guidelines are broadly useful in establishing classrooms responsive to a wide range of learning preferences.

$>$ Remember that some, but not all, of your students share your learning preferences. If a teacher were successful in his/her student days, s/he may find analytic and part-to-whole learning a breeze. Some students in the class will like those approaches as well, but students who need more creative, contextual, and whole-to-part approaches may feel like they are working in a fog unless the teacher stretches his/her own comfort zone and teaching range.

$>$ Help students reflect on their own preferences. Give students a vocabulary of learning-profile options. Let them know teacher is offering creative, practical, and analytic learning choices. Then invite students to talk about which approaches make learning most natural and effective for them. That's also a good opportunity to help students realize that not everyone in the class learns the same way, and that a good teacher works hard to honor many routes to learning, rather than only one.

$>$ Use both teacher-structured and student-choice avenues to learning-profile differentiation. Sometimes it's really effective for a teacher to think about using several intelligences as ways for students to explore or express ideas. Often, only the teacher can ensure flexible use of time or combination of presentation modes. Even when a teacher does not have time to structure or craft several learning-profile options for a lesson, much can be accomplished by asking students to make their own choices. When students are partners with teachers in making the learning environment a good fit, more is accomplished with less strain on the teacher.

> Select a few learning-profile categories for emphasis. As teacher begins to differentiate his/her instruction in response to a range of learning-profile needs, select a few categories to emphasize in the planning. The teacher may, work with Sternberg's (1985) three intelligences as you create tasks; using both contextual and factual illustrations for your students, or may employ both visual and auditory approaches to sharing information with the students. That's enough to begin. Then, whenever possible, offer the students learning decisions that they can make to further craft the classroom to match their learning needs. 
$>$ Be empathetic to students. It is difficult to "get into someone else's shoes." Teachers fail to analyze many students whose cultural background is different from his/her own. It's essential to watch individuals in the class for learning clues, to talk with them about what works and doesn't work for them, and to invite them to make suggestions or pose alternatives that seem more promising. If we can expand our vision beyond the parameters of our own private universe, we become more welcoming and effective teachers of learners who inevitably inhabit private universes different from our own.

\section{Conclusion}

Manifesting these issues in day to day class work, five proposals are provided to teachers for effective language teaching/learning in mixed ability classes. The use of pair and group work is essential to involve all the members of the class. By pairing off weaker and stronger students and involving both in the preparation and implementation of the questionnaire you should ensure maximum participation of all the students. You can then get the weaker students to interview the stronger ones and vice-versa. Of course, this may be frustrating for the stronger ones, but if they are able to see their role as that of "helper" or even mentor, it may also have a positive effect.

A second area of activity that can be productive in mixed ability classes is project work. Again, this can work successfully using mixed groups where the stronger help the weaker, but another approach is to form groups that are at approximately the same level and assign different tasks that are appropriate to the level of each group. By adjusting the complexity of the task, you can ensure that each group has a task that it can carry out successfully, thereby providing the correct level of challenge for the higher level students and not demotivating the weaker ones.

A third area is that of homework. If you set the whole class the same homework task irrespective of level, then you will have to expect very mixed results. Like progress tests, the purpose of homework should be to consolidate class work. To this end, giving weaker students less demanding tasks can help both to motivate them and to give them further practice in areas of the language which they have not yet mastered. Assigning more challenging tasks to the stronger students in the group should ensure that they remain motivated and continue to make progress. It is more work for the teacher but, ultimately, it should produce results.

Choral drilling can be an effective way of involving weaker or shy students. If applied judiciously (in other words not all the time), it can give excellent practice in rhythm and intonation, as well as reinforcing word order and grammatical structure. Finally, be diplomatic in your questioning techniques. Try to avoid putting weaker students "on the spot" by nominating them to be the first to answer a question in open class. Instead, try to encourage a culture of attentive listening in the classroom so that you ask a stronger student first and then ask a weaker student to repeat the answer. It may take time but, once this style of interaction becomes habitual, it can be very productive in terms of class dynamics.

Thus this paper thus calls for differentiation of instruction reflecting learner's needs guided by respectful tasks, flexible learning and ongoing assessment and adjustment. The clarity and quality in what the teacher differentiates in a mixed ability class is a continuous endeavour to try to meet the needs of learners with the best quality, appropriate approaches to differentiation. Differentiation is more than a strategy or series of strategies; it is a way of thinking about teaching and learning English on practical situations. Implementing quality differentiation is much more about knowing what matters to teach, realizing that learning happens in us rather than to us, continually reflecting on the 'particularness' of every student in the class. Thus discerning and implementing differentiation in teaching English is moving towards expertise by providing learners with several varieties of information/activities/learning opportunities that are best suited for virtually all students.

\section{REFERENCES}

Bowler, B. and Parminter, S. (2000) Mixed-level tasks. English Teaching Professional, Issue 15

Bowler, B. and Parminter, S. (1997) Mixed-level teaching: tiered tasks \& bias tasks. English Teaching Professional, Issue 5.

Forsten, C., Grant, J., and Hollas, B. (2002). Differentiated Instruction. Different Strategies for Different Learners. Peterborough: Crystal Springs Books. 
Ireson, J. and Hallam, S. (2001). Ability Grouping in Education. London: Paul Chapman Publishing. Prodromou, L. (1992) Mixed Ability Classes. London: Macmillan.

Tharp, R. G., and Gallimore, R. (1988).Rousing Minds to Life: Teaching, Learning and Schooling in Social Context. Cambridge, Engaland: Cambridge University Press.

Tomlinson, C. A. (1999). Mapping a route toward differentiated instruction. Educational Leadership, 57 (1), 12-16.

\section{AUTHOR'S BIOGRAPHY}

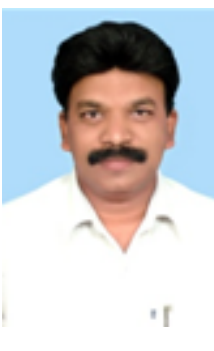

Dr. K. Yugandhar, Associate Professor of English, has received Ph.D. in English from Jawaharlal Nehru Technological University, Hyderabad, India. He has been teaching English language and literature to graduate and post graduate students for the past eighteen years. Most of his research work focuses on interlacing technology with pedagogical concepts to improve the quality of Education in general and English Language Teaching in particular. He received credentials in ELT from Osmania University, Andhra University, Kakatiya University and Central Institute of English and Foreign Language, Andhra Pradesh, India. 